\title{
3 Research Square

\section{Reactive enteric glial cells participate in paralytic ileus by damaging nitrergic neurons during endotoxemia}

$\mathrm{Na} \mathrm{Li}$

The First Affiliated Hospital of Xi'an Jiaotong University

Jing Xu

The First Affiliated Hospital of Xi'an Jiaotong University

Hui Gao

The First Affiliated Hospital of Xi'an Jiaotong University

Yuxin Zhang

The First Affiliated Hospital of Xi'an Jiaotong University

Yansong Li

The First Affiliated Hospital of Xi'an Jiaotong University

Haiqing Chang

The First Affiliated Hospital of Xi'an Jiaotong University

Shuwen Tan

The First Affiliated Hospital of Xi'an Jiaotong University

Shuang Li

The First Affiliated Hospital of Xi'an Jiaotong University

Qiang Wang ( $\square$ dr.wangqiang@139.com )

The First Affiliated Hospital of Xi'an Jiaotong University

\section{Research Article}

Keywords: Gut, Motility, Enteric glial cell, Apoptosis, Lipopolysaccharide, Sepsis

Posted Date: March 22nd, 2022

DOI: https://doi.org/10.21203/rs.3.rs-1036165/v3

License: (c) (i) This work is licensed under a Creative Commons Attribution 4.0 International License.

Read Full License 


\section{Abstract \\ Background}

Paralytic ileus is common in patients with septic shock, which causes high morbidity and mortality. Enteric neurons and enteric glial cells (EGCs) regulate intestinal motility, but little is known about their interaction in endotoxemia. We aim to investigate whether reactive EGCs have harmful effects on enteric neurons and participate in intestinal motility disorder in mice during endotoxemia.

\section{Methods}

Endotoxemia was induced by lipopolysaccharide (LPS) intraperitoneal injection in mice. And fluorocitrate (FC) was administered before LPS injections to inhibit the reactive EGCs. The effects of reactive EGCs on intestinal motility were analyzed by motility assays in vivo and colonic migrating motor complexes (CMMCs) ex vivo. The number of enteric neurons was evaluated by immunofluorescent staining HuCD, nNOS and ChAT in vivo. In addition, we stimulated EGCs with IL-1 $\beta$ and TNF-a in vitro and cultured the primary enteric neurons in the conditioned medium, detecting the apoptosis and morphology of neurons through staining TUNEL, cleaved Caspase-3 protein and Anti- $\beta$-III tubulin.

\section{Results}

Intestinal motility and peristaltic reflex can be improved by the inhibition of reactive EGCs in vivo. There is an increased density of the neuronal population in the colonic myenteric plexus significantly while the reactive EGCs are inhibited, especially the nitrergic neurons. In vitro, the enteric neurons cultured in the conditioned medium of reactive EGCs had significantly more apoptotic rate and less dendritic complexity and number of primary neurites.

\section{Conclusion}

Reactive enteric glial cells participated in paralytic ileus by damaging nitrergic neurons during endotoxemia. It could provide a novel therapeutic strategy for intestinal motility disorders during endotoxemia or sepsis.

\section{Introduction}

Sepsis is a life-threatening organ dysfunction caused by the host's dysregulated response to infection[1]. The mortality rate of sepsis and septic shock has commonly been quoted as ranging from $25-60 \%[2]$. Intestinal motility disorder, often manifests as paralytic ileus, is a common complication following sepsis and septic shock. It can cause bacteria accumulation in the intestine, and promote bacterial translocation. In turn, the occurrence of bacterial translocation will induce multiple organ dysfunction 
syndromes (MODS) and lead to high mortality[3]. Thus improving intestinal motility is critical during sepsis treatment[4]. Intestinal motility is regulated by the enteric nervous system (ENS), a complex network of neurons and glial cells, that mainly resides in the submucosal and myenteric plexus[5]. There is evidence that dysfunction, degeneration, or loss of myenteric neurons will cause several intestinal motility disorders [6, 7]. Enteric glial cells (EGCs), as the most abundant cells in the ENS, provide nutritional support for enteric neurons, promote the formation and function of synapses, and maintain neuronal survival[8].

EGCs undergo a dramatic transformation called the "reactive glial phenotype" in response to intestinal infection with bacteria[9], viruses and inflammatory mediators[10, 11]. However, there is a controversy regarding the function of reactive EGCs. Previous studies have shown EGCs may have dual protective and harmful effects. For instance, the intestinal ischemia-reperfusion injury (IRI) leads to the significant upregulation of glial fibrillary acidic protein (GFAP), the EGC reactivity marker. That presents a beneficial effect on neurons through the increase of glial cell line-derived neurotrophic factor (GDNF) [12, 13]. On the contrary, a study from Gulbransen's group provided evidence that glial reactivity as a driver of enteric neurodegeneration caused the death of enteric neurons through purinergic pathways in colitis induced by dinitrobenzene sulfonic acid (DNBS) [14]. As for endotoxemia, it has been confirmed that lipopolysaccharide (LPS) increasing leads to proinflammatory cytokines release and myenteric neurons apoptosis in vitro[15]. In addition, systemic LPS administration also induces an increase in intestinal GFAP and S100b expression[16]. While the association between reactive EGCs and the loss of enteric neurons is still an issue under discussion. That is to say, it is unclear whether reactive EGCs are beneficial or harmful to the enteric neurons in endotoxemia mice.

In this study, we investigated the effect of reactive EGCs on intestinal motility and enteric neuron function in an endotoxemia model in vivo, and observed the effect of reactive EGCs on the growth and survival rate of enteric neurons under an inflammatory condition in vitro. We observed that LPS-induced reactive EGCs are harmful to the enteric neurons during endotoxemia and are associated with colonic transit delay, which might provide a novel strategy for prevention or treatment of LPS-induced intestinal paralysis and other relevant intestinal motility disorders.

\section{Materials And Methods}

\section{Animals}

C57BL/6 mice (male, 6 8 weeks old, weight 20 23 g) were obtained from the Experimental Animal Center of Xi'an Jiaotong University (Xi'an, China) and housed in a temperature-controlled and humiditycontrolled room with a 12:12 hour light: dark cycle, and provided with food and water. All procedures were approved by the Institutional Animal Care and Use Committees at Xi'an Jiaotong University (Xi'an, China).

\section{FC treatment and endotoxemia model}


Animals were randomly divided into 3 groups: Con: vehicle control, normal saline, LPS: lipopolysaccharide, LPS + fluorocitrate (FC): LPS injection after intraperitoneal injections of FC. A schematic diagram of the experiments undertaken in this study was illustrated in Supplementary Figure S1. First, vehicle or FC (Sigma, St. Louis, MO) was injected intraperitoneally twice per day $(20 \mu \mathrm{mol} / \mathrm{kg}$ body weight, 9 AM and 6 PM) for $7 \mathrm{~d}$ as described by Nasser et al [17]. The details of FC preparation were presented in Supplementary information 1 . Then, mice were injected intraperitoneally with vehicle (controls) or with $20 \mathrm{mg} / \mathrm{kg}$ LPS (Sigma-Aldrich, E. coli 055:B55, USA) in a $0.2 \mathrm{ml}$ volume on the morning of the eighth day. Animals were observed and evaluated at least twice a day for post-treatment care until sacrifice, including breath, body temperature and activity. Gastrointestinal or colonic motility was measured until $48 \mathrm{hr}$ later. Finally, Animals were euthanized by cervical dislocation.

\section{Assessment of gastrointestinal motility}

\subsection{Stool frequency and fluid content}

According to the previous method[18], each mouse was placed in a clear cage for $1 \mathrm{hr}$. Fecal pellets were collected, counted, and weighed (wet weight). These were dried overnight at $60^{\circ} \mathrm{C}$ and weighed again (dry weight). Fluid content $(\%)=100 \% \times$ (wet weight-dry weight) $/$ wet weight.

\subsection{Colon bead assay}

Distal colon transit was assessed using glass beads ( $2 \mathrm{~mm}$ in diameter) as previously described[18], and executed $48 \mathrm{hr}$ after the LPS injection. After being overnight fasted, mice were anesthetized with inhalation of isoflurane and a single bead was inserted through the anus and pushed $2 \mathrm{~cm}$ towards the oral by a customized needle with a silicon cannula (1.9 mm in diameter) (Cadence Inc., Cat. No. 9921, Staunton, USA). Then, the needle was withdrawn lightly and the bead expulsion latency was obtained. The time required to eject the bead was measured as an estimate of colonic motility.

\subsection{Whole-gut transit}

Whole intestinal transit time was measured following the previous report with a little modification[19] and executed $48 \mathrm{hr}$ after the LPS injection. Male mice (8 weeks) have fasted only with access to water for 18 hr before the experiment. $0.2 \mathrm{~mL}$ of a solution containing $6 \%(\mathrm{w} / \mathrm{v})$ Carmine (Sigma-Aldrich, C1022, USA) and $0.5 \%(\mathrm{w} / \mathrm{v})$ methylcellulose (Sigma-Aldrich, M0262, USA) dissolved in ultrapure water was orally administered to each mouse and left undisturbed in individual cages with food and water ad libitum. During $2 \mathrm{hr}$ after gavage, pellets coloration was checked regularly every $20 \mathrm{~min}$. Time elapsed from gavage until the appearance of the first red pellet was obtained.

\subsection{Colonic migrating motor complexes measuredin vitro}

According to the previous method[20], the entire colon $(5 \sim 6 \mathrm{~cm}, \mathrm{n}=6)$ was dissected from the mouse and flushed to remove fecal content with Krebs solution. Then the empty colon was mounted in a horizontal organ bath with oxygenated Krebs solution at $35 \sim 36^{\circ} \mathrm{C}$ and maintained intraluminal pressure at 1 2 
$\mathrm{cmH}_{2} \mathrm{O}$. Preparations were equilibrated for $30 \mathrm{~min}$ and four 15-minute videos of contractile activity were captured via a video camera (Logitech, Newark, USA) positioned $7 \sim 8 \mathrm{~cm}$ above the gut. Finally, these videos were converted to spatiotemporal maps via MATLAB (MathWorks, USA). The frequency of colonic migrating motor complexes (CMMCs) as well as the velocity and length of their propagation were analyzed by a researcher blinded to the test groups.

\section{Cell cultures}

\subsection{Enteric glial cell line}

The rat enteric glial cell line CRL2690 (American Type Culture Collection, Manassas, VA, USA) was cultured in DMEM supplemented with $10 \%$ fetal bovine serum (FBS, Gibco Life Technologies, USA), $1 \mathrm{mM}$ glutamine (Gibco Life Technologies, USA), and penicillin/streptomycin (Gibco Life Technologies, USA).

\subsection{Primary enteric glial cells}

The isolation, identification, and culture of primary EGCs were performed as previously described[21]. In brief, the colonic tissue was collected from newborn mice (1 2 days old, C57BL/6 mice), and cells were cultured in DMEM-F-12 supplemented with $10 \%$ FBS, $1 \mathrm{mM}$ glutamine and $100 \mathrm{IU} / \mathrm{ml}$ penicillin/streptomycin. More details are in Supplementary information 2. They were passaged to new plates after 12 14 $\mathrm{d}$ for purity assay and the following experiments. Culture consisted of approximately $90 \%$ of enteric glia, as judged by immunolabelling with a chicken antibody specific for GFAP (1:500, GeneTex, GTX85454, USA) and rabbit antibody for S100b protein (1:100, GeneTex, GTX57757, USA) (Supplementary Figure S2).

\subsection{Primary enteric neurons}

The isolation and culture of enteric neurons are similar to that of primary EGCs. The difference is that the colonic tissue was collected from embryonic day 14 15 (E14 15) rats, and cells were cultured in a neurobasal medium containing $2 \mathrm{mM}$ glutamine, $1 \mathrm{mM}(100 \mathrm{lU} / \mathrm{ml})$ penicillin/streptomycin, and $1 \mathrm{mM} \mathrm{B}$ 27 supplement. The purity of neurons is also more than $90 \%$ after $12 \sim 14 \mathrm{~d}$, staining with mouse antiHuC/D primary antibody (1:100; Invitrogen) (Supplementary Figure S3).

\section{Conditioned medium experiments}

IL-13 (80 ng/ml, Peprotech, AF-211-11B, USA) and TNFa (60 pg/ml, Peprotech, AF-315-01A, USA) were used to induce EGCs into reactive for $24 \mathrm{hr}$ according to the previous study[21]. Briefly, the enteric glial cell line was culture about $48 \mathrm{hr}$ in DMEM supplemented with $10 \% \mathrm{FBS}, 1 \mathrm{mM}$ glutamine, and penicillin/streptomycin until the cell attachment rate was up to $70 \sim 80 \%$. Then, we changed the media into the serum-free one supplemented with $80 \mathrm{ng} / \mathrm{ml} \mathrm{IL-1 \beta}$ and $60 \mathrm{pg} / \mathrm{ml}$ TNFa for $24 \mathrm{hr}$. Next, the medium containing cytokines was removed and replaced with a fresh neurobasal medium for another 24 $\mathrm{hr}$. At this time, the reactive EGCs conditioned medium (ECM) was centrifuged at $1000 \mathrm{rpm}$ for $5 \mathrm{~min}$, filtered through a $0.22 \mu \mathrm{m}$ syringe filter ( $0.22 \mathrm{uM}$ filter, Thermo, USA), and conserved at $-80^{\circ} \mathrm{C}$ until use. 
The conditioned medium of control (resting) EGCs was collected as above process except supplementary with IL-1 $\beta$ and TNFa.

\subsection{Detection of apoptosis}

To detect apoptosis, TUNEL staining was carried out using the fluorescein tagged In Situ Cell Death kit (Promega, G3250, USA) according to the procedures of specification. Cells suspension was obtained after isolating enteric neurons from colons of fetal mice, this was counted using a classic hemocytometer. Primary enteric neurons were plated about $4 \times 10^{4}$ cells $/ \mathrm{cm}^{2}$ in 24-well plates and grown for 12 14 $\mathrm{d}$ after maturing in the neurobasal medium. They were treated with the conditioned medium of control (resting) and reactive EGCs respectively. $48 \mathrm{hr}$ after the treatment, neurons were fixed in $4 \%$ PFA for $20 \mathrm{~min}$ at $25^{\circ} \mathrm{C}$ and then cleared with PBS. The next steps were according to the procedures of the specification.

\subsection{Neurite formation assay}

Primary enteric neurons were plated about 1,000 cells $/ \mathrm{cm}^{2}$ in 24-well plates when cell suspension was obtained. The neurobasal medium was replaced with the conditioned medium of control and reactive EGCs until enteric neurons were grown for $8 \sim 9 \mathrm{~d}$. Then, enteric neurons were fixed and stained with antibodies against the neuron-specific beta III Tubulin (TuJ-1, Abcam, ab78078, USA) $72 \mathrm{hr}$ after incubation. For analysis of neurite formation, Sholl analysis was used to assess the complexity of neurites. Pictures of TuJ-1-labeled cells were taken under the confocal microscope (Olympus, FV1000, Japan) with $40 \times$ objective and a template of concentric circles distant from 10 to $500 \mu \mathrm{m}(10 \mu \mathrm{m}$ interval) from the ganglion center was overlaid on the ganglion using Image $\mathrm{J}$ software. The number of primary neurites and branching points was also counted. For each group ( 3 biological replications), 5 ganglia were analyzed.

\section{Immunofluorescent staining}

Whole-mount longitudinal muscle/myenteric plexus (LMMP) preparations of colonic myenteric plexus were prepared according to a published method in Tricia H. Smith et al[22]. An entire colon was divided into two parts, and half part of each colon was used as LMMP preparations, and the other part was for Western blot. After washing in phosphate-buffered saline, colon LMMP preparations that separated from 1-1.5-cm colonic fragments were fixed in $4 \%$ paraformaldehyde (PFA) $1 \mathrm{hr}$ and then permeabilized with $0.3 \%$ Triton-X for 40 min before immunostaining. Preparations were blocked with $10 \%$ goat serum for $1 \mathrm{hr}$ and exposed to primary antibodies: chicken anti-GFAP (1:500, GeneTex, GTX85454, USA), mouse antiHuC/D (1:100, Invitrogen, 16A11, USA) for labeling the general population of myenteric neurons, goat anti-choline acetyltransferase (ChAT, 1:200, Millipore, AB144P, USA) for labeling cholinergic neurons, and rabbit anti-neuronal nitric oxide synthase (nNOS, 1:200, GeneTex, GTX133403, USA) for labeling nitrergic neurons. Preparations were incubated with primary antibodies for $16-24 \mathrm{hr}$, visualized with speciesspecific secondary antibodies (Alexa Fluor 488 or 594, 1:500) and mounted.

\section{Confocal Image Acquisition and Analysis}


Images of the myenteric ganglia were taken under the FluoView 1000 confocal microscope (Olympus, Tokyo, Japan). A computer-controlled motorized stage was used to scan images (20x or 40x objective) without projections of Z-stacks, and the exposure brightness, contrast, and time were maintained for each photomicrograph. At least, 3 images that were captured with a $20 \times$ or $40 \times$ objective were counted from each animal ( $n=6$ biological replications). ImageJ (version 2.0) was used to analyze the fluorescent intensity and neuronal counts. For quantification of enteric neurons, 3 ganglia were randomly selected from each LMMP preparation, 3 preparations for each animal, and 3 animals in each treatment group. In each ganglion, the number of HuC/D-immunoreactive neuronal bodies and nNOS-immunoreactive neurons was manually counted in a blind fashion. In addition, the intensity fluorescence of ChAT was detected by ImageJ, along with several adjacent background readings. Then, the CTCF (corrected total cellular fluorescence) $=$ [integrated density - (area of selected cell $\times$ mean fluorescence of background readings)] was calculated[23]. All the studies were performed in a double-blind fashion.

\section{Western blot analysis}

Protein samples were extracted from colonic tissue in RIPA buffer containing complete protease and phosphatase inhibitor cocktail. After assessing the protein content of each sample by BCA Protein Assay kit (Thermo Fisher Scientific, 23227, USA), they were separated on 10\% SDS-PAGE gels and transferred to PVDF membranes. After blocking, the blots were incubated with anti-GFAP (1:10000, GeneTex, GTX100850, USA) primary antibody overnight at $4^{\circ} \mathrm{C}$. Subsequently, the membrane was incubated with a secondary antibody (anti-rabbit IgG-horseradish peroxidase, 1:2000, GeneTex, GTX213110-01, USA) followed by visualized with enhanced chemiluminescence. The signals on the blots were detected with Tanon 5200 Multi (Minhang District, Shanghai Municipality, China). $\beta$-actin was used as an internal standard. Immunoblots were quantified by Image $\mathrm{J}$ software (version 2.0).

\section{Statistical Analysis}

Results are presented as mean \pm Standard Error of Mean (SEM). All statistical analysis was conducted using Prism 7.0 (GraphPad, San Diego, USA). The Student's $t$-test was used to determine statistical differences between each experimental group and the control group data. One-way ANOVA with Sidak's multiple comparisons test was used for the data with group numbers over two. $P<0.05$ was considered significant and denoted by *.

\section{Results}

\section{LPS induced EGCs reactivity and it was inhibited by FC in mice}

We assayed GFAP expression of colonic tissue in LPS-injected animals, as it is a typical identification marker of enteric glia and astrocytes to indicate their reactivity. As expected, results of Western blot showed that GFAP expression was significantly upregulated after the LPS injection compared with the control group (Fig. $1 \mathrm{a}$ and $\mathrm{b}$, control vs. LPS, $P<0.01$ ). FC is a metabolic compound that makes EGCs metabolism static [17]. To testify whether EGCs are no longer reactive in the mice treated with FC, we 
injected LPS and assessed the protein expression of GFAP $48 \mathrm{hr}$ later. Western blot analysis showed that FC treatment significantly reduced the expression of GFAP in colon tissue compared with the LPS group, while it has no significant difference with the control one (Fig. 1a and b, mean FC + LPS vs. LPS, $P<$ 0.001 ; vs. control, $P>0.05$ ). In addition, we isolated the LMMPs from colon tissue and detected the intensity of GFAP expression in the myenteric nerve plexus by immunostaining. Compared with the control group, the intensity of GFAP increased in the LPS group (Fig. 1C-f, mean LPS vs. Control, $P<0.05$ ). However, it decreased in the LPS plus FC group relative to the LPS group (Fig. 1c-f, mean FC + LPS vs. LPS, $P<0.05)$. Thus, it indicated that EGCs convert into a reactive state after LPS injection in mice, while, FC treatment impeded this process.

\section{Inhibition of reactive EGCs improves intestinal motility and peristaltic reflex in LPS-injected animals}

To determine whether the reactive EGCs are involved in the regulation of GI motility, we measured fecal pellet output, propulsive colorectal motility, total gastrointestinal transit time (TGIT), fluid content in vivo. As shown in Figure 2, LPS significantly reduced gastrointestinal motility, which includes stool frequency (mean control $8.83 \pm 0.83$, vs. LPS $2.50 \pm 0.43$ pullets/hr, Fig. $2 \mathrm{a}, P<0.01$ ), colon transit time (mean control $49.83 \pm 9.63 \mathrm{~s}$, vs. LPS $1044 \pm 235.10 \mathrm{~s}$, Fig. $2 \mathrm{~b}, P<0.001$ ) and TGIT (mean control 72.50 $\pm 4.61 \mathrm{~min}$, vs. LPS $541.20 \pm 63.00 \mathrm{~min}$, Fig. $2 \mathrm{c}, P<0.0001$ ). Stool frequency (mean FC + LPS $5.33 \pm 0.56$ vs. LPS group, Fig. 3a, $P<0.05$ ), colon transit time (mean FC + LPS $188.80 \pm 60.35$, vs. LPS group, Fig. 3b, $P<0.01$ ) and TGIT (mean FC + LPS $201.30 \pm 44.18$ min vs. LPS group, Fig. 3c, $P<0.01$ ) were significantly alleviated by FC treatment, comparing with the group only with LPS injection. Besides, there is no significant difference in stool water content between the control and the LPS mice, and between the LPS mice and the LPS mice treated with FC (mean control $0.63 \pm 0.037$, vs. LPS $0.61 \pm 0.04$; LPS vs. FC + LPS $0.48 \pm 0.07$, Fig. 2 d, $P>0.05$ ).

CMMCs, which are dependent on ENS [24], were investigated in the isolated preparations of colons to determine whether the observed changes in motility are due to an intrinsic ENS defect. Spatiotemporal maps of CMMCs were constructed and analyzed (Fig. 2e-g), showing that frequency (mean control $1.15 \pm$ $0.19 \mathrm{CMMCs} / \mathrm{min}$, vs. LPS $0.36 \pm 0.06 \mathrm{CMMCs} / \mathrm{min}$, Fig. $2 \mathrm{~h}, P<0.001$ ) and velocity (mean control 22.95 $\pm 3.90 \mathrm{~mm} / \mathrm{min}$, vs. LPS $5.30 \pm 0.36 \mathrm{~mm} / \mathrm{min}$, Fig. $2 \mathrm{i}, P<0.001$ ) were significantly decreased in the LPS group compared with the control group. However, both of them were back to normal when treated with FC (frequency, mean FC + LPS $0.78 \pm 0.04 \mathrm{CMMCs} / \mathrm{min}$ vs. LPS, $P<0.05$; velocity, mean FC + LPS $17.27 \pm$ $1.15 \mathrm{~mm} / \mathrm{min}$, vs. LPS, $P<0.05)$. To sum up, the reactive EGCs slow down intestinal transit and disrupt the peristaltic reflex, while FC can mitigate the deficiency induced by LPS.

\section{Inhibiting reactive EGCs reduces the loss of nitrergic neurons in the myenteric plexus of LPS-injected animals}

To study how reactive EGCs affect enteric neurons in LPS-injected animals, the density of the general neuronal population (HuC/D-immunoreactive) in the colonic myenteric plexus was detected among the control, LPS, and LPS plus FC groups. LPS reduced the number of general neurons by $28 \%$ compared 
with the control mice (mean control $662.85 \pm 55.71 / \mathrm{mm}^{2}$, vs. LPS $476.19 \pm 62.22 / \mathrm{mm}^{2}$, Fig. 3a and b, $P<$ 0.05). However, the neuronal population did not decrease in the FC plus LPS group, but increased significantly compared with the LPS group (mean FC + LPS $719.05 \pm 50.16 / \mathrm{mm}^{2}$, vs. LPS group, $P<$ 0.05). To define whether the reactive EGCs affect the subpopulation of cholinergic and nitrergic neurons, we measured ChAT and nNOS expression in the colonic myenteric plexus by immunofluorescence staining. LPS reduced the population of nNOS neurons per square millimeter of colonic LMMPs (mean control $292.40 \pm 27.82 / \mathrm{mm}^{2}$, vs. LPS $\left.156.40 \pm 24.62 / \mathrm{mm}^{2}, P<0.05\right)$, which reversed to baseline after FC treatment (mean FC + LPS $251.40 \pm 23.39 / \mathrm{mm}^{2}$, vs. LPS group, Fig. 3c, $P<0.05$ ). No statistically significant difference was found in ChAT fluorescence intensity between the LPS mice and the LPS mice treated with FC (Fig. 3d, $P>0.05$ ). These observations suggested that the reactive EGCs cause enteric neuron loss, especially nitrergic neurons in LPS-injected animals.

\section{Reactive EGCs induce primary enteric neurons into apoptosis in vitro}

It has been shown that reactive EGCs lead to a decrease of enteric neurons in the myenteric plexus in vivo. We studied how reactive EGCs influence the state of enteric neurons in vitro. Firstly, IL-1 $\beta$ and TNFa were used to stimulate the enteric glial cell line to develop a serum-free culture model for the reactive EGCs in vitro, mimicking the pathological process in LPS-injected animals (Fig. 4a-d). Meanwhile, it was identified that IL-1 $\beta$ and TNFa made primary EGCs reactive (Supplementary Figure S4). Next, purified enteric neurons were incubated with Neurobasal medium, the conditioned medium of resting or reactive EGCs. Then the cell apoptosis was assessed using TUNEL tests and cleaved Caspase-3 protein staining. The TUNEL assay showed that primary enteric neurons revealed $27.54 \pm 5.28 \%$ positive apoptotic neurons at $48 \mathrm{hr}$ after cultured in the conditioned medium of reactive EGCs compared with $3.06 \% \pm 0.34$ for cultures in the conditioned medium of resting EGCs (Fig. 5a and b, $P<0.01$ ). Immunofluorescence of cleaved Caspase-3 protein displayed that $6.84 \pm 0.35 \%$ positive apoptotic neurons cultured in the conditioned medium of reactive EGCs compared with $3.46 \pm 1.16 \%$ for neurons incubated with the conditioned medium of the resting EGCs (Fig. $5 \mathrm{c}$ and d, $P<0.01$ ).

\section{Reactive EGCs disrupt neurites formation of primary enteric neurons in vitro}

To test if reactive EGCs affect neurites formation of enteric neurons in vitro, primary enteric neurons were incubated with the conditioned medium of resting or reactive EGCs and observed the morphology through TuJ-1 immunostaining (Fig. 6a). The dendritic complexity of neurons cultured in reactive EGCs conditioned medium significantly declined compared with those grown in the resting EGCs conditioned medium (Fig. 6b, $P<0.05$ ). In addition, the primary neurites number of neurons cultured in reactive EGCs conditioned medium decreased by $54.17 \%$ (+resting EGCs $6.00 \pm 0.58$, vs. +reactive EGCs $2.75 \pm 0.85$, Fig. $6 \mathrm{c}, P<0.05)$ and the number of branches was also reduced by $77.14 \%$, comparing with neurons grown in the resting EGCs conditioned medium (+resting EGCs $19.25 \pm 1.03$, vs. +reactive EGCs $4.40 \pm 0.87$, Fig. $6 \mathrm{~d}, P<0.0001)$. Neurons cultured in reactive EGCs conditioned medium tended to show shorter neurites compared to those grown in the resting EGCs conditioned medium (+resting EGCs $141.80 \pm 30.22$, vs. 
+reactive EGCs $72.03 \pm 20.21$, Fig. 6 e, $P>0.05$ ), However, there was no significant difference between them (Supplementary Figure S5).

\section{Discussion}

In this study, we demonstrated that reactive EGCs caused a significant decrease in intestinal motility via increasing the apoptosis of nitrergic enteric neurons in LPS-injected animals. However, this tendency was reversed, when the function of reactive EGCs was inhibited by FC. In addition, reactive EGCs also disrupted the neurites formation of primary enteric neurons in vitro. Together, our results indicate that the reactive EGCs could cause damage to the enteric neuron during endotoxemia, which deteriorates the intestinal motility disorder, suggesting that inhibition of the reactive EGCs could be a therapeutic strategy for the treatment of LPS-induced intestinal paralysis and other intestinal motility disorders.

Early research showed that EGCs play an important role in regulating and protecting enteric neurons, and dysfunction of EGCs will break the intestinal homeostasis, leading to a series of gastrointestinal disorders[25]. Previous studies demonstrate that enteric glia could be activated by bacteria, which will respond to an immune reaction in the gastrointestinal tract and release ATP[14], inflammatory cytokines[26], and prostaglandin, etc[27]. However, whether the reactive EGCs participate in neurodegenerative processes and whether the interaction between EGCs and neurons influences intestinal motility is yet under discussion. To elucidate this question, we tested the intestinal motility of mice injected LPS and FC plus LPS, as well as the number of colonic LMMP neurons. Compared with the control, there was a significant delay of intestinal transit accompanied by a significant loss of neurons after the LPS injection. The result revealed that inhibition of EGC reactivity could improve intestinal motility and prevent neurons from losing. Thus, we inferred that the reactive EGCs were associated with the decrease of enteric neurons. Meanwhile, it has been shown that ENS plays a significant role in motility regulation[28] and the loss of enteric neurons causes intestinal dysmotility[7]. Therefore, if the reactive EGCs are inhibited, the loss of neurons would be alleviated as well as the intestinal dysmotility.

GFAP, a glial fibrillary acidic protein, is the typical identification marker of enteric glia and astrocytes, whose expression in mature EGCs is modulated by cell differentiation, inflammation, and injury[29]. Increased GFAP has been observed in ulcerative colitis, Crohn's disease[25], and Parkinson's disease[30]. Astrocytes and EGCs can be induced into reactive by cytokines and LPS[31, 32]. In line with previous research, there was an upregulation of the GFAP expression in our study [16]. However, GFAP is dynamic and its observed expression varies depending on glial state[33], subtype[34], and genetic targeting strategy[35]. Changes in morphology or GFAP expression are not a definitive indication of a reactive glial phenotype, since the functional change is more crucial for a different cell phenotype. Additionally, LPS triggers immune responses in endotoxemia, leading to a massive release of cytokines such as IL-1 $\beta$ and TNF- $a[4,36]$. In our study, we stimulated the enteric glial cell line and primary EGCs with IL-1 $\beta$ and TNF-a in vitro to mimic the inflammatory response induced by LPS in vivo. As expected, the GFAP expression levels increased significantly. To make a definitive indication of a reactive glial phenotype, we collected 
the conditioned medium of the reactive EGCs and incubated it with the primary enteric neurons, detecting effects of reactive EGCs on neurons survival and neurites' formation.

EGCs were primarily considered as a component to provide structural support for the enteric neural net. Currently, it has been confirmed that EGCs could release nerve growth factor (NGF), neurotrophin 3 (NT-3), and GDNF to maintenance and contribute to the survival of enteric neurons[37, 38]. Interestingly, glia transforms into a reactive phenotype in response to intestinal infection with bacteria or viruses, inflammatory mediators[39]. The function of reactive EGCs, though unlike the central nervous system (CNS), is still poorly understood. As shown for the CNS, two different types of reactive astrocytes termed "A1" and "A2" were induced by neuroinflammation and ischemia respectively[40]. In addition, A1 reactive astrocytes become neurotoxic, leading to the neuron's death[41]. As for ENS, the intestinal ischemiareperfusion injury (IRI) leads to the significant upregulation of GFAP, which may present a beneficial effect on neurons, because GDNF increased under this condition $[12,13]$.

On the contrary, a study from Gulbransen's group provided evidence that glial reactivity is a driver of enteric neurodegeneration in colitis[14]. Besides, Andromeda's group used human EGCs from GI-surgical specimens and treated them with LPS to study the gene expression and relevant functions. Their results showed that the "reactive human EGC phenotype" leads to alterations of important molecular and functional signaling pathways that could disrupt GI motility[42]. After all, there is still a lack of study about the influence of reactive EGCs on enteric neurons. In our study, we used a conditioned medium of reactive EGCs to interfere with primary enteric neurons, and the results indicated that the reactive EGCs damaged enteric neurons through increasing neurons' apoptosis and disrupting neurites' formation. On the other hand, it suggested that EGCs might release some specific substances to be harmful to enteric neurons. Thus, potential substances or targets that reactive EGCs damage enteric neurons could be found in the future study, which could be a potential new therapeutic target to modulate the intestinal dysmotility of patients suffering from sepsis or endotoxemia, or other diseases associated with motility disorders.

Fluoroacetate (FAC) and its metabolite FC were important tools that have been used to define the role of astrocytes in central[ $[43,44]$ and peripheral neural networks previously[45, 46]. Also, FC can be selectively taken up by enteric glia in the intestine [47] and cause a reversible and selective disruption of glial function owing to a fall in glia ATP levels through inhibiting the tricarboxylic acid TCA cycle. However, it does not influence glial and neuronal morphology in both the myenteric and submucosal plexuses of the ileum and colon in mice treated with $20 \mu \mathrm{mol} / \mathrm{kg} \mathrm{FC[17].} \mathrm{In} \mathrm{our} \mathrm{research,} \mathrm{EGCs} \mathrm{were} \mathrm{not} \mathrm{induced} \mathrm{into}$ reactive by LPS after FC administration, meanwhile, gastrointestinal motility and the number of enteric neurons were not decreased anymore, comparing with the LPS group. Hence, it suggested that the reactive EGCs appear to an adverse effect on intestinal motility in LPS-injected animals.

We found that the amount of total and nitrergic neurons in the myenteric nerve clusters was decreased, except for cholinergic neurons, which is similar to a previous study[6]. The ENS contains many different types of neurons[48]. Cholinergic neurons and nitrergic neurons are mainly involved in intestinal motility 
regulation[49]. At least $70 \%$ of all myenteric neurons are cholinergic, which excite smooth muscle[50]. While most enteric neurons that inhibit smooth muscle contain nitric oxide synthase 1 (NOS1) [50]. This might seem contradictory. On the one hand, it may be relevant to the interaction and coordination among different kinds of enteric neurons, and the broken balance of intestinal neural networks might cause intestinal disorders. On the other hand, this study only focused on two kinds of neurons, changes in other kinds of neurons during endotoxemia are still unclear. All these need further research.

\section{Conclusions}

In conclusion, the present data indicated that reactive enteric glial cells are involved in paralytic ileus through promoting nitrergic enteric neuronal apoptosis and impeding the formation of neurites during endotoxemia. These findings could provide a novel therapeutic strategy for intestinal motility disorders, including LPS-induced intestinal paralysis. In addition, the specific mechanism about how the reactive EGCs damage enteric neurons needs further study.

\section{Declarations}

Funding This work was supported by funding from the National Natural Science Foundation of China (Nos. 81774113, 81974540), Beijing, China, and the Clinical Research Award of the First Affiliated Hospital of Xi'an Jiaotong University (No. XJTU1AF-CRF-2016-003), Xi'an, China.

Competing Interests The authors declare that they have no conflict of interest.

Author Contributions Qiang Wang and Shuang Li designed experiments and developed methodologies; $\mathrm{Na} \mathrm{Li}$, Hui Gao and Jing Xu performed the research and wrote the manuscript; Yuxin Zhang and Haiqing Chang analyzed and interpreted data; Qiang Wang, Jing Xu and Shuwen Tan revised the manuscript.

Data Availability The datasets used and/or analyzed during the current study are available from the corresponding author on reasonable request.

Ethics approval All procedures performed in studies involving animals were approved by the ethical standards of Institutional Animal Care and Use Committees of Xi'an Jiaotong University, Xi'an, China. Mice received humane care following the Guidelines for the Care and Use of Laboratory Animals of the National Institutes of Health.

Consent to participate Not applicable.

Consent for publication Not applicable

Acknowledgments We want to express our gratitude to Professor Shengxi Wu and his colleagues (Department of Neurobiology, Air Force Medical University, Xi'an, Shaanxi Province, China) who shared equipment and reagents generously in getting the preliminary data. 


\section{References}

1. Jacob JA (2016) New sepsis diagnostic guidelines shift focus to organ dysfunction. JAMA 315:739740. https://doi.org/10.1001/jama.2016.0736

2. Cecconi M, Evans L, Levy M and Rhodes A (2018) Sepsis and septic shock. The Lancet 392:75-87. https://doi.org/10.1016/S0140-6736(18)30696-2

3. Königsrainer I, Türck MH, Eisner F, T M, J H, M K, D Z and J. G (2011) The gut is not only the target but a source of inflammatory mediators inhibiting gastrointestinal motility during sepsis. Cell Physiol Biochem 28:753-760. https://doi.org/10.1159/000335769

4. Overhaus M, To"gel S, Pezzone MA and Bauer AJ (2004) Mechanisms of polymicrobial sepsisinduced ileus. Am J Physiol Gastrointest Liver Physiol, 287:G685694.https://doi.org/10.1152/ajpgi.00359.2003

5. Furness JB, Callaghan BP, Rivera LR and Cho H-J (2014) The enteric nervous system and gastrointestinal innervation: integrated local and central control. Adv Exp Med Biol 817:39-71. https://doi.org/10.1007/978-1-4939-0897-4_3

6. Reichardt F, Chassaing B, Nezami BG, Li G, Tabatabavakili S, Mwangi S, Uppal K, Liang B, VijayKumar M, Jones D, Gewirtz AT and Srinivasan S (2017) Western diet induces colonic nitrergic myenteric neuropathy and dysmotility in mice via saturated fatty acid- and lipopolysaccharideinduced TLR4 signaling. J Physiol 595:1831-1846.https://doi.org/10.1113/JP273269

7. White JP, Xiong S, Malvin NP, Khoury-Hanold W, Heuckeroth RO, Stappenbeck TS and Diamond MS (2018) Intestinal dysmotility syndromes following systemic infection by flaviviruses. Cell 175:11981212 e12.https://doi.org/10.1016/j.cell.2018.08.069

8. Le Berre-Scoul C, Chevalier J, Oleynikova E, Cossais F, Talon S, Neunlist M and Boudin H (2017) A novel enteric neuron-glia coculture system reveals the role of glia in neuronal development. The Journal of Physiology 595:583-598.https://doi.org/10.1113/JP271989

9. Turco F, Sarnelli G, Cirillo C, Palumbo I, De Giorgi F, D'Alessandro A, Cammarota M, Giuliano M and Cuomo R (2014) Enteroglial-derived S100B protein integrates bacteria-induced Toll-like receptor signalling in human enteric glial cells. Gut 63:105-15.https://doi.org/10.1136/gutjnl-2012-302090

10. von Boyen GB, Schulte N, Pfluger C, Spaniol U, Hartmann C and Steinkamp M (2011) Distribution of enteric glia and GDNF during gut inflammation. BMC Gastroenterol

11:3.https://doi.org/10.1186/1471-230X-11-3

11. Coelho-Aguiar Jde M, Bon-Frauches AC, Gomes AL, Verissimo CP, Aguiar DP, Matias D, Thomasi BB, Gomes AS, Brito GA and Moura-Neto V (2015) The enteric glia: identity and functions. Glia 63:92135.https://doi.org/10.1002/glia.22795

12. Xiao W, Wang W, Chen W, Sun L, Li X, Zhang C and Yang H (2014) GDNF is involved in the barrierinducing effect of enteric glial cells on intestinal epithelial cells under acute ischemia reperfusion stimulation. Mol Neurobiol 50:274-89.https://doi.org/10.1007/s12035-014-8730-9 
13. McKeown SJ, Mohsenipour M, Bergner AJ, Young HM and Stamp LA (2017) Exposure to GDNF enhances the ability of enteric neural progenitors to generate an enteric nervous system. Stem Cell Reports 8:476-488.https://doi.org/10.1016/j.stemcr.2016.12.013

14. Brown IA, McClain JL, Watson RE, Patel BA and Gulbransen BD (2016) Enteric glia mediate neuron death in colitis through purinergic pathways that require connexin-43 and nitric oxide. Cell Mol Gastroenterol Hepatol 2:77-91.https://doi.org/10.1016/j.jcmgh.2015.08.007

15. Coquenlorge S, Duchalais E, Chevalier J, Cossais F, Rolli-Derkinderen M and M. N (2014) Modulation of lipopolysaccharide-induced neuronal response by activation of the enteric nervous system. $J$ Neuroinflammation 11:202.https://doi.org/10.1186/s12974-014-0202-7

16. da Cunha Franceschi R, Nardin P, Machado CV, Tortorelli LS, Martinez-Pereira MA, Zanotto C, Goncalves CA and Zancan DM (2017) Enteric glial reactivity to systemic LPS administration: Changes in GFAP and S100B protein. Neurosci Res 119:1523.https://doi.org/10.1016/j.neures.2016.12.005

17. Nasser Y, Fernandez E, Keenan CM, Ho W, Oland LD, Tibbles LA, Schemann M, MacNaughton WK, Ruhl A and Sharkey KA (2006) Role of enteric glia in intestinal physiology: effects of the gliotoxin fluorocitrate on motor and secretory function. Am J Physiol Gastrointest Liver Physiol 291:G91227.https://doi.org/10.1152/ajpgi.00067.2006.

18. McClain J, Grubisic V, Fried D, Gomez-Suarez RA, Leinninger GM, Sevigny J, Parpura V and Gulbransen BD (2014) Ca2+ responses in enteric glia are mediated by connexin-43 hemichannels and modulate colonic transit in mice. Gastroenterology 146:497-507 e1.https://doi.org/10.1053/j.gastro.2013.10.061

19. Nagakura Y, Naitoh Y, Kamato T, Yamano M and Miyata K (1996) Compounds possessing 5-HT3 receptor antagonistic activity inhibit intestinal propulsion in mice. Eur J Pharmacol 311:6772.https://doi.org/10.1016/0014-2999(96)00403-7

20. Swaminathan M, Hill-Yardin E, Ellis M, Zygorodimos M, Johnston LA, Gwynne RM and Bornstein JC (2016) Video Imaging and Spatiotemporal Maps to Analyze Gastrointestinal Motility in Mice. J Vis Exp:53828.https://doi.org/10.3791/53828

21. von Boyen GB, Steinkamp M, Reinshagen M, Schafer KH, Adler G and Kirsch J (2004) Proinflammatory cytokines increase glial fibrillary acidic protein expression in enteric glia. Gut 53:222-8.https://doi.org/10.1136/gut.2003.012625

22. Smith TH, Ngwainmbi J, Grider JR, Dewey WL and Akbarali HI (2013) An In-vitro Preparation of Isolated Enteric Neurons and Glia from the Myenteric Plexus of the Adult Mouse. Journal of Visualized Experiments. https://doi.org/10.3791/50688

23. D'Errico F, Goverse G, Dai Y, Wu W, Stakenborg M, Labeeuw E, De Simone V, Verstockt B, GomezPinilla PJ, Warner M, Di Leo A, Matteoli G and Gustafsson JA (2018) Estrogen receptor beta controls proliferation of enteric glia and differentiation of neurons in the myenteric plexus after damage. Proc Natl Acad Sci U S A 115:5798-5803.https://doi.org/10.1073/pnas.1720267115 
24. Spencer NJ, Bywater RA and GS. T (1998) Evidence that myoelectric complexes in the isolated mouse. Neurosci Lett 250:153-156.https://doi.org/10.1016/s0304-3940(98)00461-3

25. Cornet A, Savidge TC, Cabarrocas J, Deng WL, Colombel JF and Lassmann H (2001) Enterocolitis induced by autoimmune targeting of enteric glial cells: a possible mechanism in Crohn's disease? Proc Natl Acad Sci U S A. 98:13306-13311.https://doi.org/10.1073/pnas.231474098

26. Rühl A, Franzke S, Collins S and Stremmel W (2001) Interleukin-6 expression and regulation in rat enteric glial cells. Am J Physiol Gastrointest Liver Physiol 280:G1163-G1171. https://doi.org/10.1152/ajpgi.2001.280.6.G1163

27. Pochard C, Coquenlorge S, Freyssinet $M$ and Naveilhan $P$ (2018) The multiple faces of inflammatory enteric glial cells: is Crohn's disease a gliopathy? Am J Physiol Gastrointest Liver Physiol. 315:G1G11.https://doi.org/10.1152/ajpgi.00016.2018

28. Furness JB (2012) The enteric nervous system and neurogastroenterology. Nat Rev Gastroenterol Hepatol 9:286-94.https://doi.org/10.1038/nrgastro.2012.32

29. Ruhl A (2005) Glial cells in the gut. Neurogastroenterol Motil 17:77790.https://doi.org/10.1111/j.1365-2982.2005.00687.x

30. Clairembault T, Kamphuis W, Leclair-Visonneau L, Rolli-Derkinderen M, Coron E, Neunlist M, Hol EM and Derkinderen P (2014) Enteric GFAP expression and phosphorylation in Parkinson's disease. J Neurochem 130:805-15.https://doi.org/10.1111/jnc.12742

31. Sofroniew MV (2014) Multiple roles for astrocytes as effectors of cytokines and inflammatory mediators. Neuroscientist 20:160-72. https://doi.org/10.1177/1073858413504466

32. Bhave S, Gade A, Kang M, Hauser KF, Dewey WL and Akbarali HI (2017) Connexin-purinergic signaling in enteric glia mediates the prolonged effect of morphine on constipation. FASEB J 31:2649-2660.https://doi.org/10.1096/fj.201601068R

33. Delvalle NM, Dharshika C, Morales-Soto W, Fried DE, Gaudette L and Gulbransen BD (2018) Communication Between Enteric Neurons, Glia, and Nociceptors Underlies the Effects of Tachykinins on Neuroinflammation. Cell Mol Gastroenterol Hepatol 6:321-344.

https://doi.org/10.1016/j.jcmgh.2018.05.009

34. Boesmans W, Lasrado R, Vanden Berghe P and Pachnis V (2015) Heterogeneity and phenotypic plasticity of glial cells in the mammalian enteric nervous system. Glia 63:229-41. https://doi.org/10.1002/glia.22746

35. Grubisic V and Gulbransen BD (2017) Enteric glial activity regulates secretomotor function in the mouse colon but does not acutely affect gut permeability. J Physiol 595:3409-3424. https://doi.org/10.1113/JP273492

36. Leger T, Charrier A, Moreau C, Hininger-Favier I, Mourmoura E, Rigaudiere JP, Pitois E, Bouvier D, Sapin V, Pereira B, Azarnoush K and Demaison L (2017) Early sepsis does not stimulate reactive oxygen species production and does not reduce cardiac function despite an increased inflammation status. Physiol Rep 5. https://doi.org/10.14814/phy2.13231 
37. Long X, Li M, Li LX, Sun YY, Zhang WX, Zhao DY and Li YQ (2018) Butyrate promotes visceral hypersensitivity in an IBS-like model via enteric glial cell-derived nerve growth factor. Neurogastroenterol Motil 30:e13227. https://doi.org/10.1111/nmo.13227

38. Chow CFW, Che S, Qin HY, Kwan HY, Bian ZX and Wong HLX (2019) From psychology to physicality: how nerve growth factor transduces early life stress into gastrointestinal motility disorders later in life. Cell Cycle 18:1824-1829. https://doi.org/10.1080/15384101.2019.1637203

39. Ochoa-Cortes F, Turco F, Linan-Rico A, Soghomonyan S, Whitaker E, Wehner S, Cuomo R and Christofi FL (2016) Enteric glial cells: a new frontier in neurogastroenterology and clinical target for inflammatory bowel diseases. Inflamm Bowel Dis 22:433-49. https://doi.org/10.1097/MIB.0000000000000667

40. Zamanian JL, Xu L, Foo LC, Nouri N, Zhou L, Giffard RG and Barres BA (2012) Genomic analysis of reactive astrogliosis. J Neurosci 32:6391-410. https://doi.org/10.1523/JNEUROSCI.6221-11.2012

41. Liddelow SA, Guttenplan KA, Clarke LE, Bennett FC, Bohlen CJ, Schirmer L, Bennett ML, Munch AE, Chung WS, Peterson TC, Wilton DK, Frouin A, Napier BA, Panicker N, Kumar M, Buckwalter MS, Rowitch DH, Dawson VL, Dawson TM, Stevens B and Barres BA (2017) Neurotoxic reactive astrocytes are induced by activated microglia. Nature 541:481-487. https://doi.org/10.1038/nature21029

42. Linan-Rico A, Turco F, Ochoa-Cortes F, Harzman A, Needleman BJ, Arsenescu R, Abdel-Rasoul M, Fadda P, Grants I, Whitaker E, Cuomo R and Christofi FL (2016) Molecular signaling and dysfunction of the human reactive enteric glial cell phenotype: implications for GI infection, IBD, POI, neurological, motility, and GI disorders. Inflamm Bowel Dis 22:1812-34. https://doi.org/10.1097/MIB.0000000000000854

43. Henneberger C, Papouin T, Oliet SH and Rusakov DA (2010) Long-term potentiation depends on release of D-serine from astrocytes. Nature 463:232-6. https://doi.org/10.1038/nature08673

44. Pougnet JT, Toulme E, Martinez A, Choquet D, Hosy E and Boué-Grabot E (2014) ATP P2X receptors downregulate AMPA receptor trafficking and postsynaptic efficacy in hippocampal neurons. Neuron 83:417-430. https://doi.org/10.1016/j.neuron.2014.06.005

45. MacEachern SJ, Patel BA, Keenan CM, Dicay M, Chapman K, McCafferty DM, Savidge TC, Beck PL, MacNaughton WK and Sharkey KA (2015) Inhibiting Inducible Nitric Oxide Synthase in Enteric Glia Restores Electrogenic Ion Transport in Mice With Colitis. Gastroenterology 149:445-55.e3. https://doi.org/10.1053/j.gastro.2015.04.007

46. Wang P, Du C, Chen FX, Li CQ, Yu YB, Han T, Akhtar S, Zuo XL, Tan XD and Li YQ (2016) BDNF contributes to IBS-like colonic hypersensitivity via activating the enteroglia-nerve unit. Sci Rep 6:20320. https://doi.org/10.1038/srep20320

47. Fonnum F, Johnsen A and Hassel B (1997) Use of fluorocitrate and fluoroacetate in the study of brain metabolism. Glia 21:106-13.

48. Gershon MD (2010) Developmental determinants of the independence and complexity of the enteric nervous system. Trends Neurosci 33:446-56. https://doi.org/10.1016/j.tins.2010.06.002 
49. Furness JB (2000) Types of neurons in the enteric nervous system. J Auton Nerv Syst 81:87-96. https://doi.org/10.1016/s0165-1838(00)00127-2

50. Rao M and Gershon MD (2018) Enteric nervous system development: what could possibly go wrong? Nat Rev Neurosci 19:552-565. https://doi.org/10.1038/s41583-018-0041-0

\section{Figures}

a

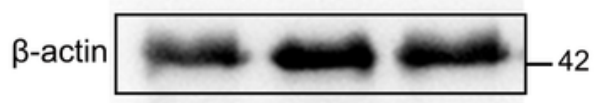

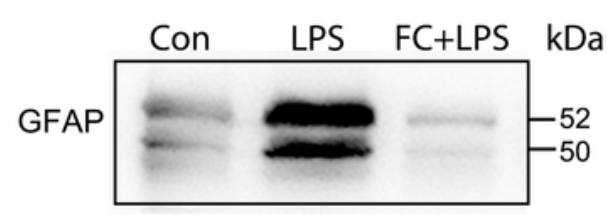

b

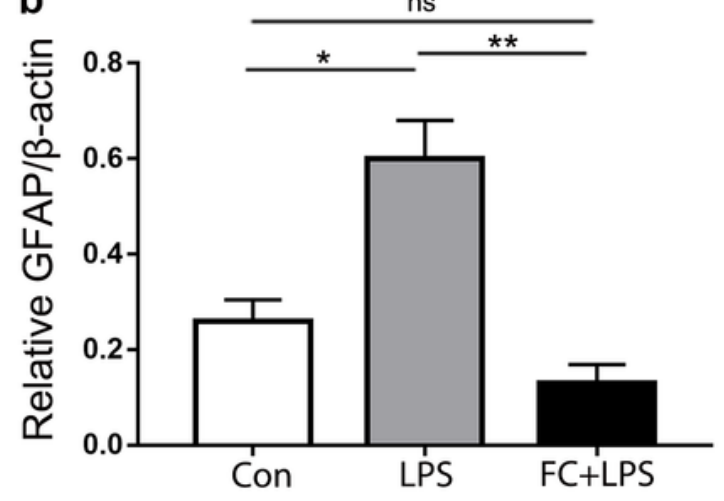

c
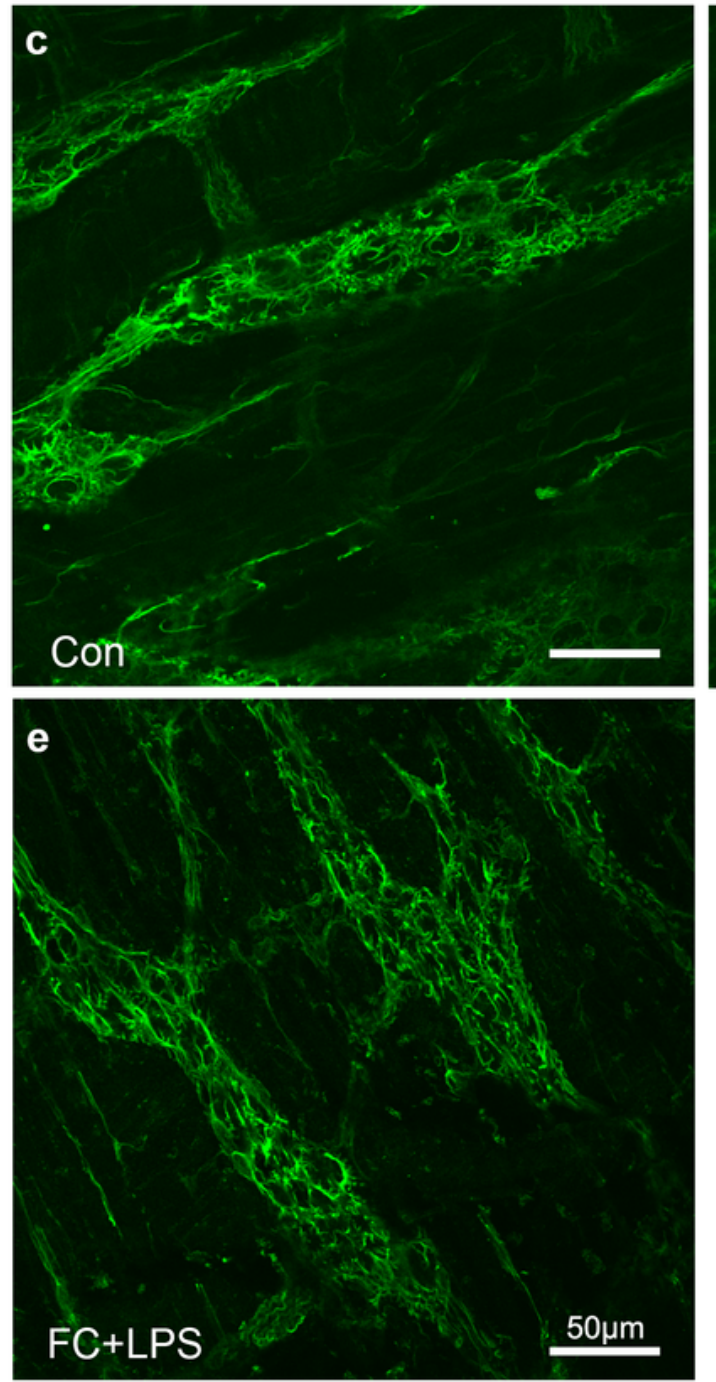

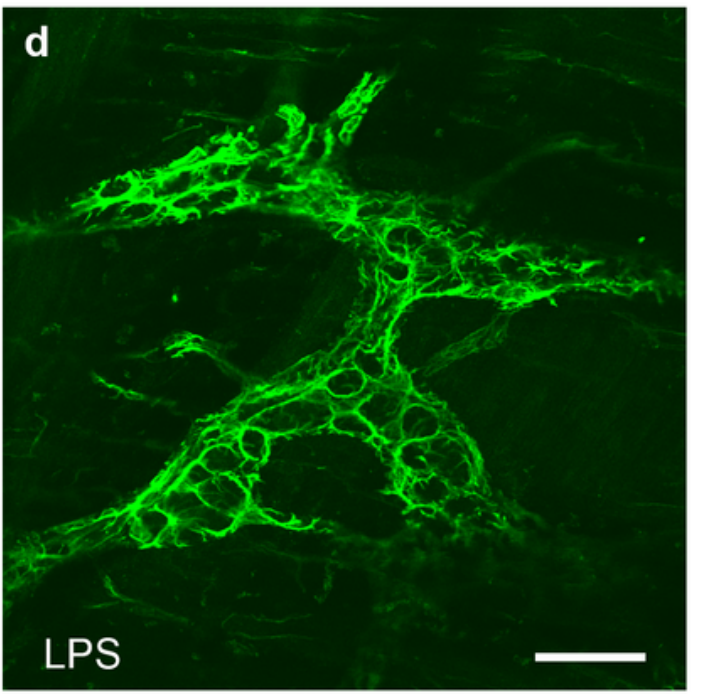

f

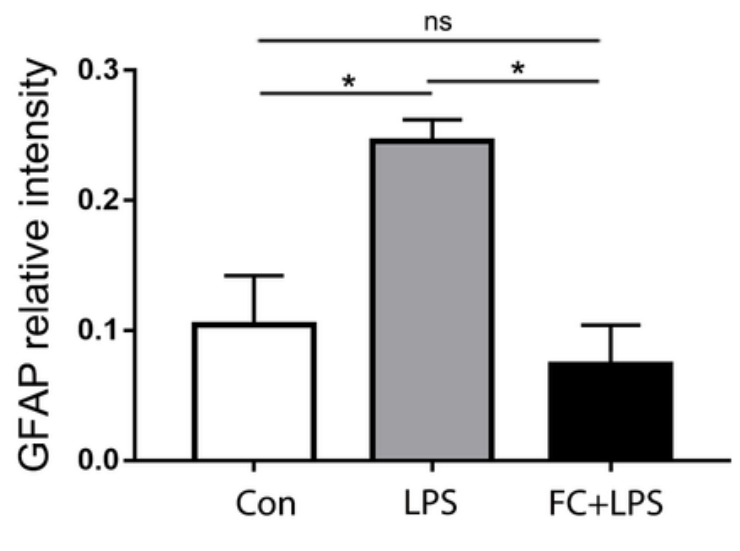




\section{Figure 1}

Effects of FC on EGCs reactivity in septic mice. (a-b) Western blot showed that the protein expression of GFAP in colon tissue increased after the LPS injection whereas it was reversed by FC treatment. (c-f) Immunostaining in the colon myenteric plexus showed that the GFAP fluorescence intensity increased in the LPS group relative to the control group, however, it was reduced in the LPS plus FC group compared with the LPS group. One-way ANOVA, $\mathrm{n}=6$ mice per group, $* P<0.05, \star \star P<0.01$, ns, no significant difference. 

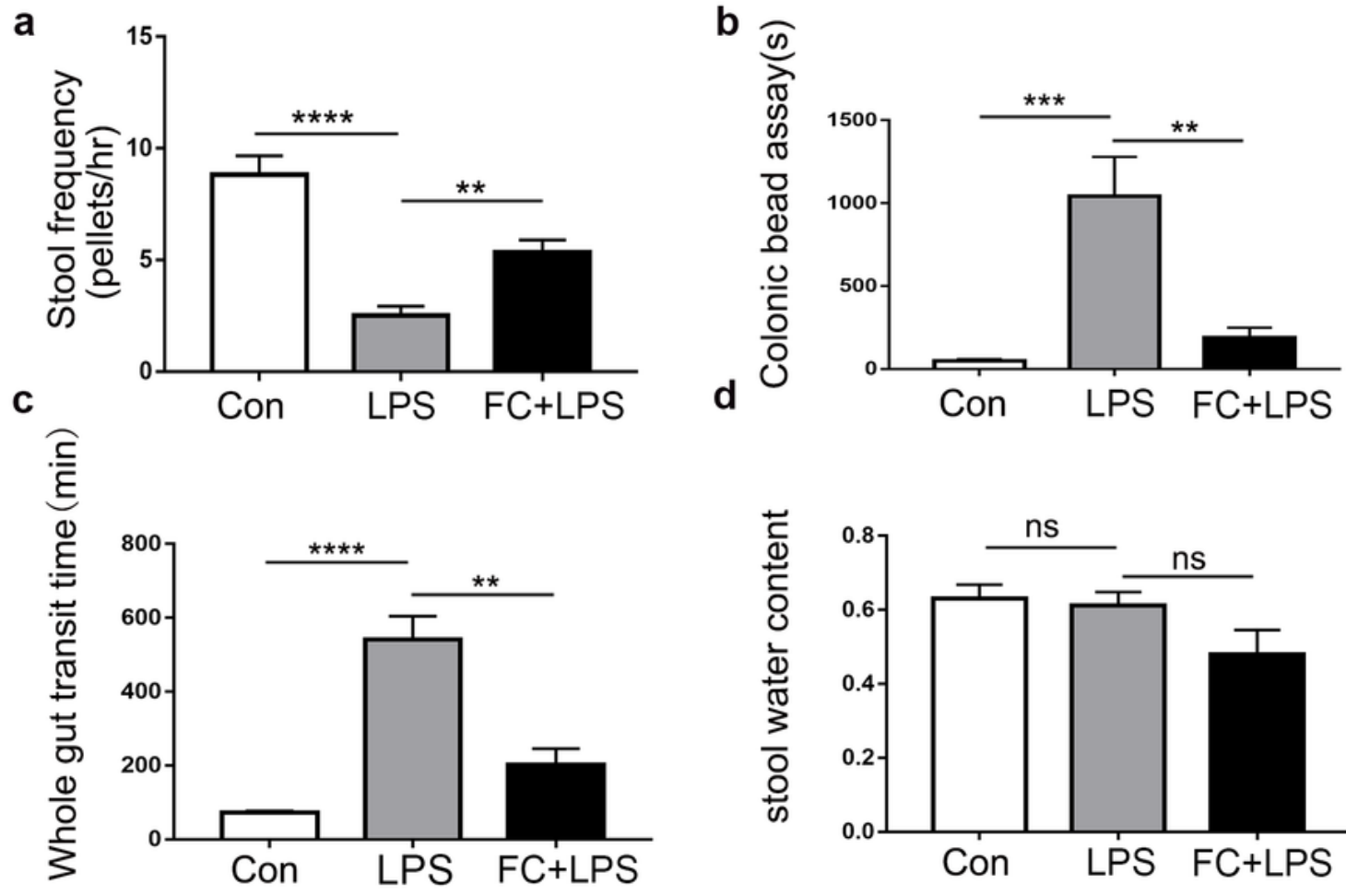

e
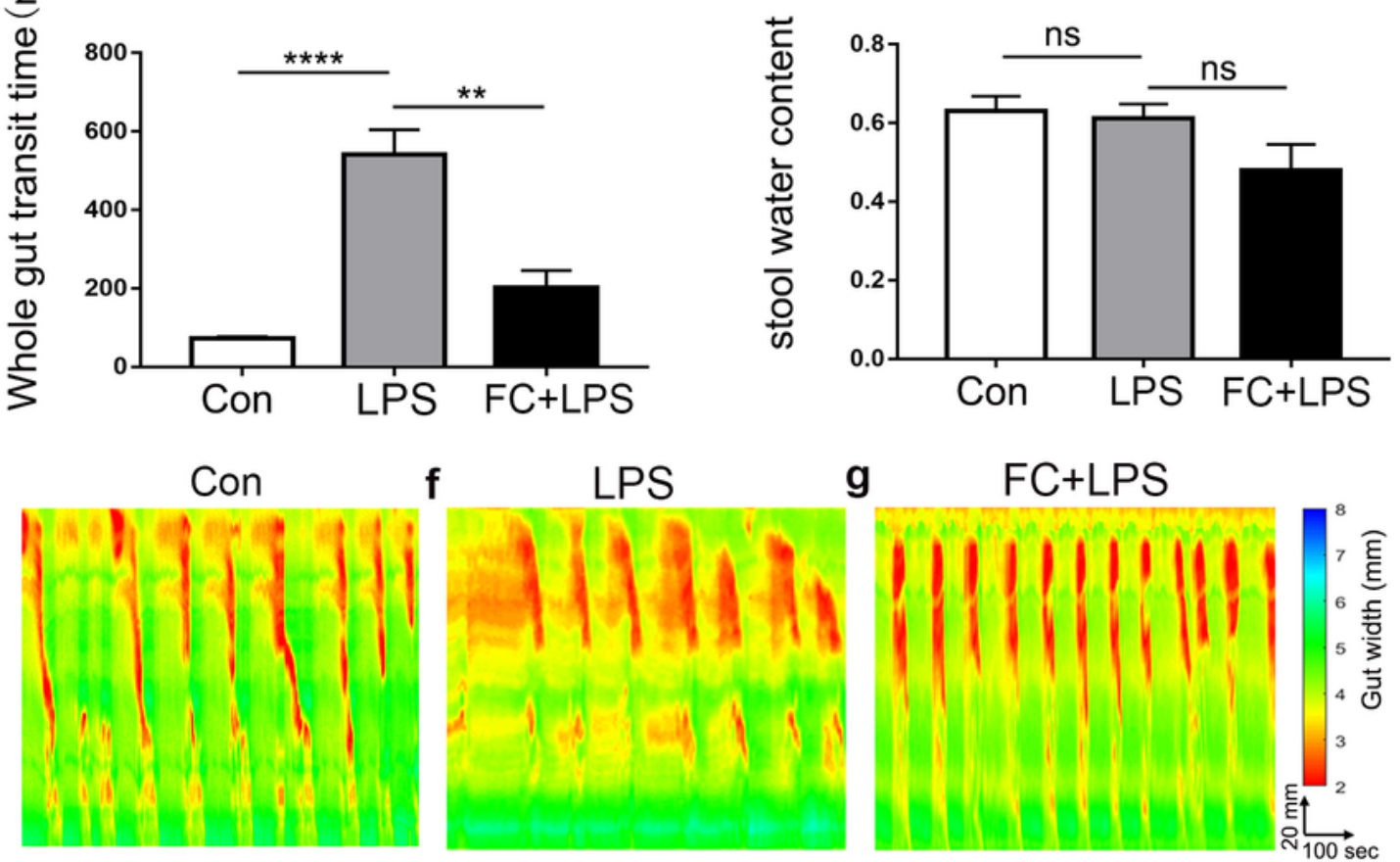

h

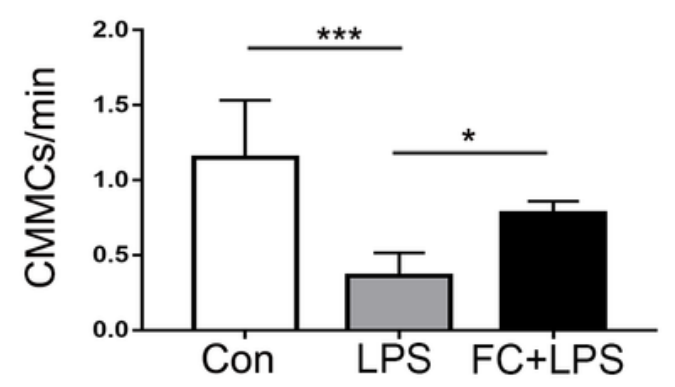

g FC+LPS

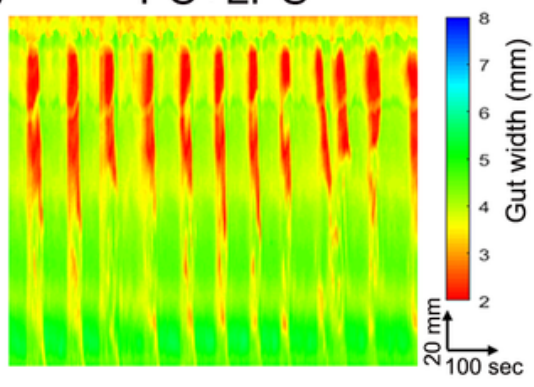

CMMC velocity

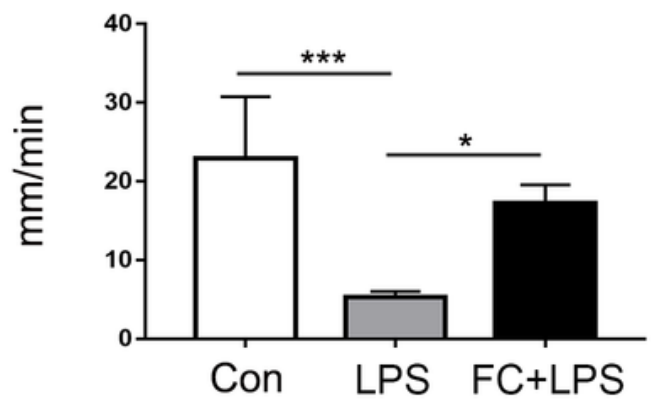

Figure 2

Effects of inhibiting reactive EGCs on intestinal motility in septic mice. The intestinal motility decreased at $48 \mathrm{hr}$ after the LPS injection and partly reversed back to normal under the condition of EGC ablation.

(a) Stool frequency, (b) Colonic bead assay(s), (c) Whole gut transit time, (d) Stool water content. (e-g) Spatiotemporal maps illustrating CMMCs recorded for control, LPS injection, and FC treatment. (h-j) LPS reduced CMMC frequency and velocity in the colon, while they were significantly improved by FC 
treatment. One-way ANOVA, $\mathrm{n}=6$ mice per group, * $P<0.05, * \star P<0.01, * \star \star * P<0.001, * \star \star \star P<0.0001, \mathrm{~ns}$, no significant difference.

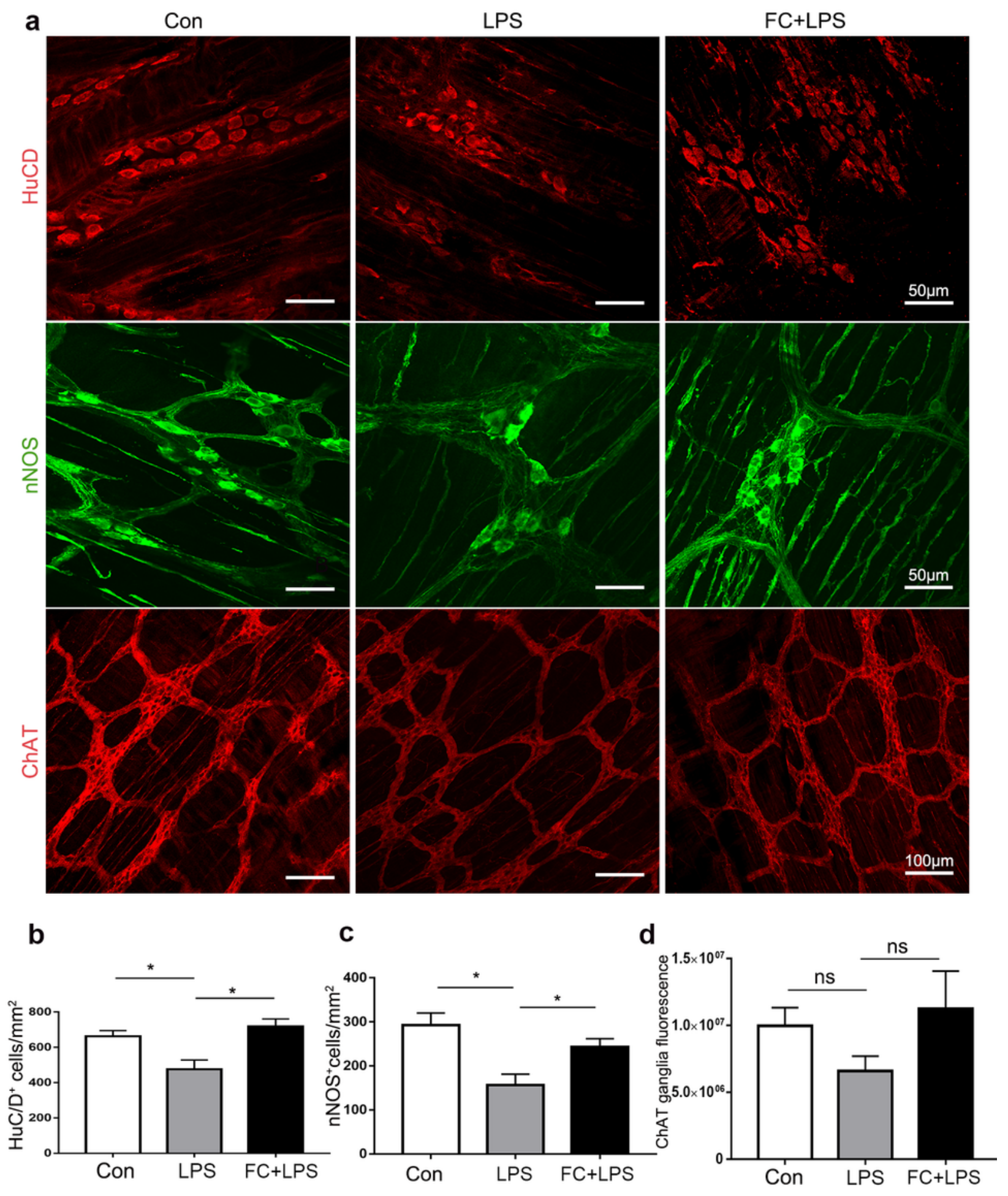

Figure 3

Effects of inhibiting reactive EGCs on the number of neurons in septic mice. (a) Representative images of immunofluorescence staining in the colonic myenteric plexus under different treatments. The number of 
the general neuronal population (HuC/D-immunoreactive) (b) and nitrergic neurons (nNOSimmunoreactive) (c) decreased at $48 \mathrm{hr}$ after the LPS injection, and was restored to normal in the FC treatment group. Myenteric ganglia fluorescence intensity (CTCF) of ChAT (d) showed no significant difference among these groups. One-way ANOVA, $\mathrm{n}=6$ mice per group, $* P<0.05$, ns, no significant difference.

a

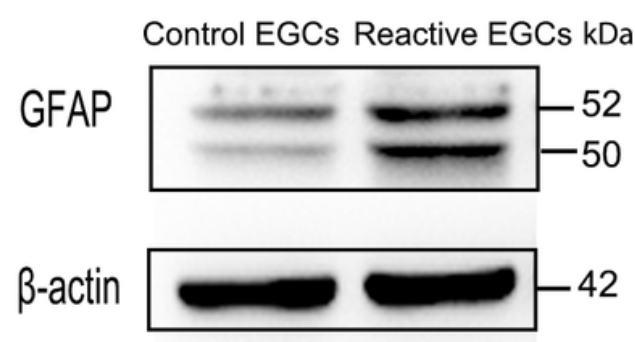

b

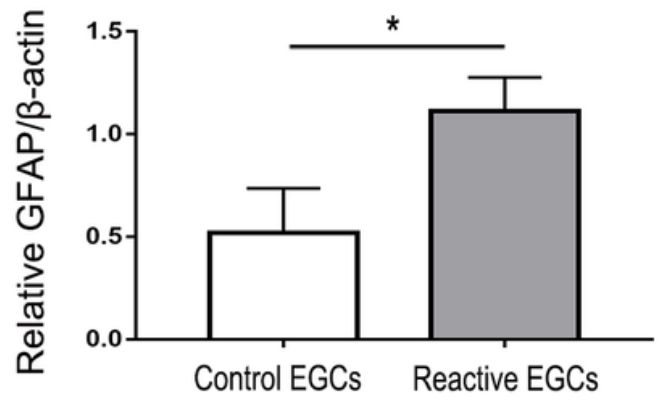

Merge

\section{Figure 4}

Reactive EGCs were induced by IL-1 $\beta$ and TNF- $a$ in vitro. (a-b) Western blot showed that GFAP expression of enteric glial cell line increased under IL-1 $\beta / T N F-a$ treatment. (c-d) Immunostaining showed higher GFAP fluorescence intensity of EGCs with IL-1 $\beta /$ TNF- $\alpha$ treatment relative to the control group. Student's $t$ test, $\mathrm{n}=3$ biological replications, * $P<0.05$. 


\section{Figure 5}

Effects of reactive EGCs on the apoptosis of primary enteric neurons. (a) The representative TUNEL staining images (the white arrows in a) showed that apoptotic cells in cultured enteric neurons with blank control (Neurobasal medium), the conditioned medium of resting EGCs, and the conditioned medium of reactive EGCs. (b) The TUNEL positive cells percentage increased at $48 \mathrm{hr}$ after cultured with the conditioned medium of reactive EGCs, compared with neurons incubated with the conditioned medium of the resting EGCs. (c-d) Fluorescence staining for the cleaved form of caspase-3 in primary enteric neurons (the yellow arrows in c) showed that more positive apoptotic neurons were observed in the conditioned medium of the reactive EGCs group than in the conditioned medium of the resting EGCs. One-way ANOVA, $\mathrm{n}=6$ biological replications, ${ }^{*} P<0.05, * \star P<0.01$, $* \star * P<0.001$, ns, no significant difference. Control, blank control (Neurobasal medium); +ECM(+resting EGCs), the conditioned medium of resting EGCs; +ECM(+reactive EGCs), the conditioned medium of reactive EGCs.

a

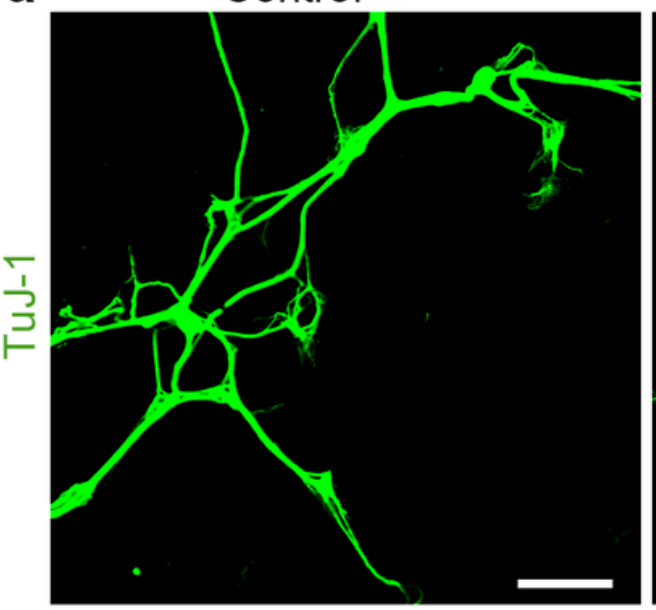

b

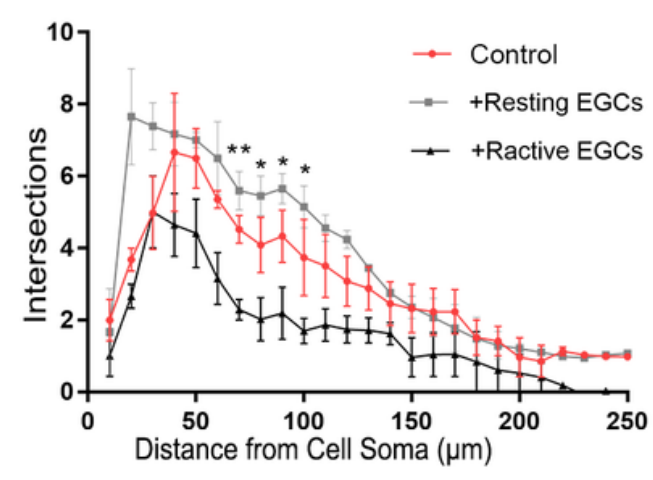

$+\mathrm{ECM}(+$ Resting EGCs)

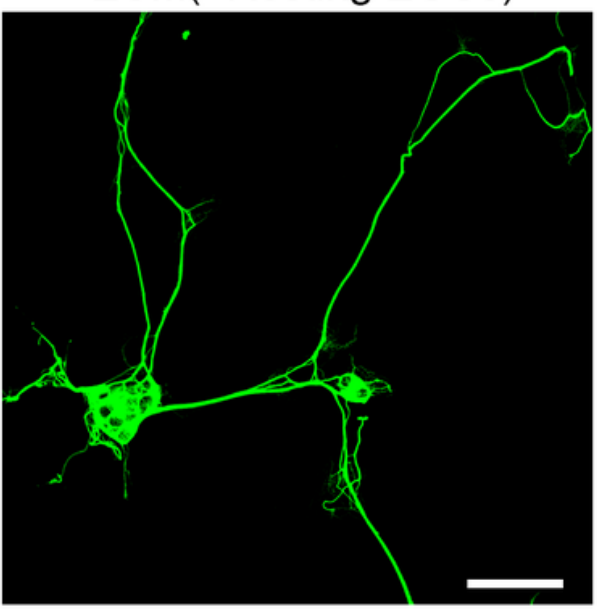

C

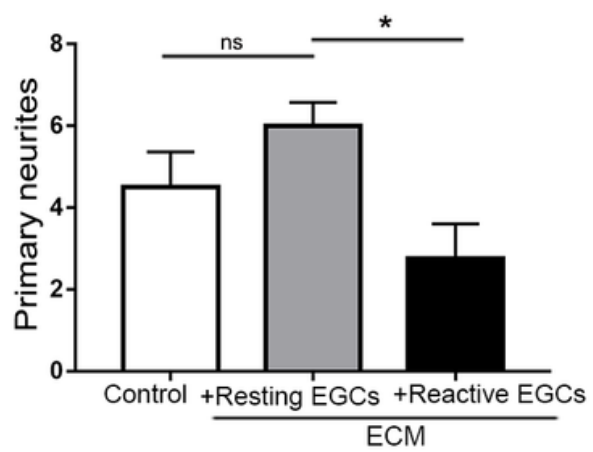

+ECM (+Reactive EGCs)

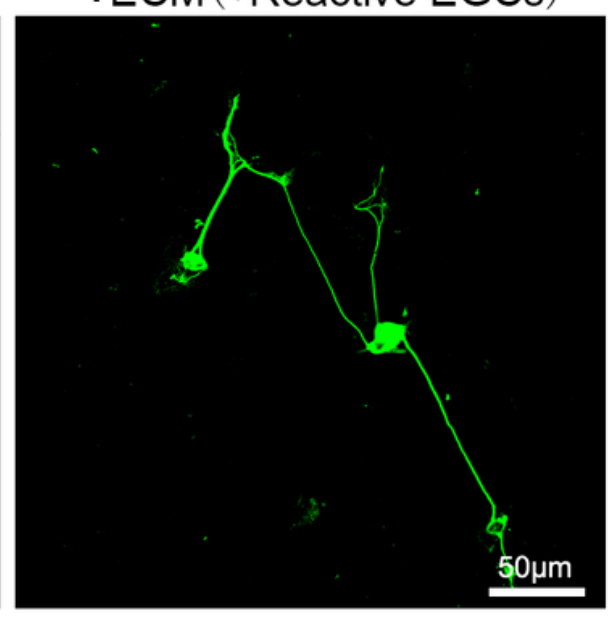

d

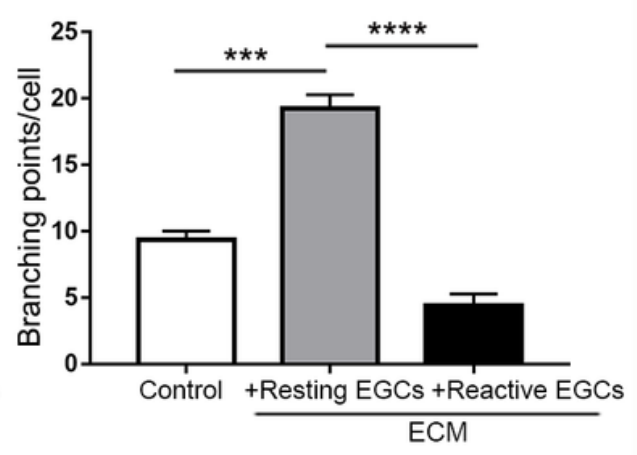

Figure 6

Effects of reactive EGCs on neurites formation in primary enteric neurons. (a) The representative immunofluorescence images of TuJ-1 to present the morphology of cultured enteric neurons under different treatments. (b) Sholl analysis showed that the dendritic complexity of primary enteric neurons 
was reduced in cultured with the conditioned medium of reactive EGCs, compared with neurons incubated with the conditioned medium of the resting EGCs. The number of primary neurites (c) and branching points (d) decreased in the medium of the reactive EGCs group relative to the group adding the conditioned medium of the resting EGCs. One-way ANOVA, $\mathrm{n}=6$ biological replications, ${ }^{\star} P<0.05, * \star * ~ P<$ $0.001, \star \star \star \star ~ P<0.0001, \mathrm{~ns}$, no significant difference. Control, blank control (Neurobasal medium); $+E C M$ (+resting EGCs), the conditioned medium of resting EGCs; +ECM(+reactive EGCs), the conditioned medium of reactive EGCs.

\section{Supplementary Files}

This is a list of supplementary files associated with this preprint. Click to download.

- SupplementaryMaterial.docx 